Tropical Journal of Pharmaceutical Research October 2021; 20 (10): 2071-2076

ISSN: $1596-5996$ (print); 1596-9827 (electronic) (C) Pharmacotherapy Group, Faculty of Pharmacy, University of Benin, Benin City, 300001 Nigeria.

\title{
Isoglycyrrhizin protects mouse lungs against acute respiratory distress syndrome via regulation of AMPK/Nrf2/ARE pathway
}

\author{
Jian Wang, Zhengliang Peng, Kailiang Huang, Jian Yin, Cheng Feng, Ting You, \\ Weihua Tan* \\ Department of Emergency, The First Affiliated Hospital of Nanhua University, Hengyang 421001, Hunan Province, China
}

*For correspondence: Email: hbbv63@163.com

Sent for review: 30 June 2021

Revised accepted: 26 September 2021

\begin{abstract}
Purpose: To study the effect of isoglycyrrhizin on LPS-mediated acute respiratory distress syndrome (ARDS) in a mouse model, as well as the associated mechanism of action.

Methods: Ninety (90) wild-type C57BL/6 male mice were randomly assigned to 3 groups, viz, control, $A R D S$ and isoglycyrrhizin groups. Pathological lesions in mice lungs were determined using H\&E staining. The $m R N A$ and protein expressions of inducible nitric oxide synthase (iNOS), heme oxygenase (HO-1), cyclooxygenase-2 (COX-2), AMP-dependent protein kinase (AMPK), serine/threonine protein kinase (Akt), glycogen synthase kinase 3 (GSK3), nucleotide-binding domain-like receptor protein 3 (NLRP3), and Nrf2 were assayed using quantitative reverse transcription polymerase chain reaction (RT-PCR) and immunoblotting, respectively.

Results: The levels of mRNA and protein expressions of INO) and COX-2 were significantly upregulated in ARDS, when compared to control, but were markedly down-regulated by isoglycyrrhizin ( $p$ $<0.05)$. Similarly, exposure of ARDS mice to isoglycyrrhizin led to upregulations of $m R N A$ and protein levels of Nrf2, NQ01, HO-1, GCLM, GCLC, p-GSK3, GSK3, p-AMPK, AMPK, p-Akt and AKT ( $<<0.05)$. Moreover, isoglycyrrhizin significantly downregulated $p-I K B$ and Nucl-p65 with respect to protein and $m R N A$ levels, but upregulated $I K B \alpha$ expression. Histopathological examination revealed that pretreatment of ARDS mice with isoglycyrrhizin significantly reduced the number of infiltrating inflammatory cells, edema and ARDS score $(p<0.05)$.

Conclusion: Isoglycyrrhizin protects mouse lungs against ARDS via regulation of AMPK/Nrf2/ARE pathway. Thus, this compound has potential for use in the treatment of ARDS.
\end{abstract}

Keywords: Acute respiratory distress syndrome, Inflammatory response, Isoglycyrrhizin, Lipopolysaccharide, Oxidative stress

This is an Open Access article that uses a funding model which does not charge readers or their institutions for access and distributed under the terms of the Creative Commons Attribution License (http://creativecommons.org/licenses/by/4.0) and the Budapest Open Access Initiative (http://www.budapestopenaccessinitiative.org/read), which permit unrestricted use, distribution, and reproduction in any medium, provided the original work is properly credited.

Tropical Journal of Pharmaceutical Research is indexed by Science Citation Index (SciSearch), Scopus, International Pharmaceutical Abstract, Chemical Abstracts, Embase, Index Copernicus, EBSCO, African Index Medicus, JournalSeek, Journal Citation Reports/Science Edition, Directory of Open Access Journals (DOAJ), African Journal Online, Bioline International, Open-J-Gate and Pharmacy Abstracts

\section{INTRODUCTION}

Respiratory diseases constitute important health problems worldwide. Acute respiratory distress syndrome (ARDS) is a life-threatening hyperinflammatory disease of the lung. Clinical symptoms of the disease include respiratory distress, refractory hypoxemia and decreased lung compliance [1]. Epidemiological data show that globally, ARDS has high incidence and 
mortality [2]. The pathogenesis of ARDS is complex, and it is thought to be caused by oxidative stress and inflammatory response induced by gram-negative bacterial infection [3]. Therefore, a new therapeutic approach will be to target oxidative stress and inflammatory response.

Various plants used in TCM have produced great benefits in the treatment of hyperinflammatory diseases [4]. Such triterpenoid and flavonoid-rich herbs exert potent antioxidant and antiinflammatory effects [4]. Isoglycyrrhizin, a flavonoid derived from licorice root, is widely used in clinical practice due to its potent antioxidant and anti-inflammatory properties [5]. This study investigated the effect of isoglycyrrhizin on LPS-induced ARDS in mice, and the mechanism involved.

\section{EXPERIMENTAL}

\section{Animals}

Wild-type C57BL/6 male mice ( $\mathrm{n}=90$; mean age $=7 \pm 1$ weeks; mean weight $=19 \pm 1 \mathrm{~g}$ ) were obtained from Guangzhou Genio Biotechnology Co. Ltd. The animals were maintained in plastic cages and given unrestricted exposure to feed and clean water in an environment with equal light and dark periods at $25{ }^{\circ} \mathrm{C}$ and $50 \%$ humidity. Approval for the study was received from the Ethics Committee of our institution (approval no. 2019073), and the study was carried out according to the guidelines of "Principles of Laboratory Animal Care" (NIH publication no. 85-23, revised 1985) [6].

\section{Experimental design}

The mice were randomly assigned to 3 groups (30 mice/group), namely, control, ARDS and isoglycyrrhizin groups. Acute respiratory distress syndrome (ARDS) was induced via intranasal injection of LPS at a dose of $5 \mathrm{mg} / \mathrm{kg}$. Mice in the isoglycyrrhizin group were pretreated intraperitoneally with isoglycyrrhizin at a dose of $30 \mathrm{mg} / \mathrm{kg} 1 \mathrm{~h}$ before ARDS induction.

\section{Histological examination of lung tissues}

Exactly $12 \mathrm{~h}$ after ARDS induction, the mice were euthanized under mild ether anesthesia. A portion of excised lung tissue (left lower lobe) was fixed in $4 \%$ formaldehyde for $24 \mathrm{~h}$. Histopathological changes were assessed based on severity of alveolar hemorrhage, alveolar edema, neutrophil infiltration or aggregation, thickening of alveolar wall, formation of hyaline membrane and infiltration of inflammatory cells.
The extent of lung damage was also determined using pathological scores: $0=$ no lesion; 1 = mild lesion; 2 = moderate lesion; 3 = severe lesion, and $4=$ extremely severe lesion. Image J analysis software was used to determine the severity of damage to lung mucosa.

\section{Collection of BALF}

Bronchoalveolar lavage fluid (BALF) is a biofluid which reflects the expressions of secreted pulmonary proteins and the products of activated cells. The trachea of each mouse was completely exposed and cut into "inverted V-shaped" orifices, and then irrigated with a syringe. Cell suspension was obtained by subjecting the fluid to centrifugation at $4{ }^{\circ} \mathrm{C}$.

\section{Determination of ROS levels in BALF}

The levels of ROS in BALF cell suspension were determined using 2, 7- dihydrodichlorofluorescein diacetate (DCFH-DA) assay. The cells were washed twice with phosphate-buffered saline (PBS) and centrifuged at $3000 \mathrm{rpm}$ for $10 \mathrm{~min}$. Then, the cell suspension was mixed with $10 \mu \mathrm{M}$ solution of DCFH-DA and incubated for $35 \mathrm{~min}$ at $37{ }^{\circ} \mathrm{C}$, followed by rinsing in PBS, and flow cytometric analysis.

\section{Biochemical analyses}

Myeloperoxidase (MPO) and SOD activities, and levels of MDA and GSH in lung tissue were measured with ELISA kits.

\section{Quantitative reverse transcription-PCR}

Total RNA extraction from BASF cells was done with TRIzol reagent. The RNA was reversetranscribed to cDNA, and the mRNA expression levels of iNOS, HO-1, COX-2, AMPK, Akt, GSK3, NLRP3, and Nrf2 were assayed using the $2^{-\Delta \Delta C t}$ method, with $\beta$-actin as internal control.

\section{Western blotting}

Total protein was extracted from the BASF cells by lysing with chilled RIPA laced with protease inhibitor. Following centrifugation of the lysate in the cold, the protein content of the supernatant was determined with BCA method. Then, 30- $\mathrm{gg}$ protein portions were resolved in SDS-PAGE, followed by electro-transfer unto PVDF membranes which were thereafter blocked by incubation with $3 \%$ fat-free milk in TBS. Thereafter, the blots were incubated overnight at $4{ }^{\circ} \mathrm{C}$ with primary antibodies for iNOS, HO-1, COX-2, AMPK, Akt, GSK3, NLRP3, Nrf2 and $\beta-$ actin (all diluted 1: 1000. Then, following TBS-T 
rinsing, the membrane was incubated with HRPlinked goat anti-rabbit $\operatorname{lgG} 2^{\circ}$ antibody for 120 min at laboratory temperature. The immunoblots were developed with X-ray film, and the bands were subjected to grayscale analysis with ImageJ Launcher software. Protein levels were expressed relative to that of $\beta$-actin which served as internal control.

\section{Statistics}

Measurement results are presented as mean \pm SEM. Comparison amongst groups was performed with Duncan's test and SNK-q test. All statistical analyses were carried out with SPSS (20.0). Values of $p<0.05$ were assumed indicative of significant differences.

\section{RESULTS}

\section{Influence of isoglycyrrhizin on histology of mouse lungs}

There were no obvious pathological changes in lungs of control mice. Histopathological examination of lung tissues of ARDS mice revealed visible blood spots, significantly thickened alveolar septum, alveolar hyperemia, edema and infiltration of inflammatory cells $(p<$ 0.05). Acute respiratory distress syndrome (ARDS) score was raised, relative to control. Pretreatment of ARDS mice with isoglycyrrhizin significantly reduced the number of infiltrating inflammatory cells, edema and ARDS score $(p<$ 0.05). These results are shown in Table 1.

\section{Effect of isoglycyrrhizin on mouse oxidative stress}

Treatment of ARDS mice with isoglycyrrhizin significantly reduced the levels of ROS and MDA, as well as activity of MPO in BALF, but it markedly increased the level of GSH and SOD activity $(p<0.05$; Table 2$)$.

\section{Effect of isoglycyrrhizin on protein expressions of pro-inflammatory factors}

The mRNA and protein expression levels of INOS) and COX-2 were significantly raised in ARDS mice, when compared to control mice, but these parameters were down-regulated by isoglycyrrhizin $(p<0.05$; Table 3$)$.

Table 1: Histopathological examination of lung tissues of ARDS mice (mean $\pm \mathrm{SD}$ )

\begin{tabular}{lc}
\hline Group & ARDS \\
\hline Control & $3.16 \pm 0.21$ \\
ARDS & $12.85 \pm 0.57^{\mathrm{a}}$ \\
Isoglycyrrhizin & $6.93 \pm 0.41^{\mathrm{ab}}$ \\
\hline${ }^{\mathrm{a} P}<0.05$, vs control mice; ${ }^{\mathrm{b}} p<0.05$, vs ARDS mice
\end{tabular}

Table 3: Expression levels of inflammatory proteins (mean \pm SD)

\begin{tabular}{lcc}
\hline Group & iNOS & COX-2 \\
\hline Control & $0.28 \pm 0.08$ & $0.38 \pm 0.10$ \\
ARDS & $1.21 \pm 0.12^{\mathrm{a}}$ & $1.14 \pm 0.15^{\mathrm{a}}$ \\
Isoglycyrrhizin & $0.35 \pm 0.06^{\mathrm{b}}$ & $0.68 \pm 0.11^{\mathrm{b}}$ \\
\hline${ }^{\mathrm{a} P}<0.05$, vs control mice; ${ }^{\mathrm{b}} p<0.05$, vs ARDS mice
\end{tabular}

Effect of isoglycyrrhizin on Nrf2 expression and its downstream antioxidant enzymes, and AMPK pathway-related proteins

Treatment of ARDS mice with isoglycyrrhizin significantly upregulated the mRNA and protein concentrations of Nrf2, NQO1, HO-1, GCLC, GCLM, p-GSK3, GSK3, p-AMPK, AMPK, p-Akt, and AKT $(p<0.05)$. These results are shown in Table 4.

Table 2: Effect of isoglycyrrhizin on mice oxidative status (mean \pm SD)

\begin{tabular}{lccccc}
\hline Group & ROS & MPO & MDA & GSH & SOD \\
\hline Control & $0.71 \pm 0.24$ & $0.52 \pm 0.16$ & $1.71 \pm 0.34$ & $438.67 \pm 41.67$ & $73.94 \pm 10.46$ \\
ARDS & $2.29 \pm 0.58^{\mathrm{a}}$ & $0.92 \pm 0.37^{\mathrm{a}}$ & $5.41 \pm 0.74^{\mathrm{a}}$ & $213.64 \pm 30.56^{\mathrm{a}}$ & $35.79 \pm 8.14^{\mathrm{a}}$ \\
Isoglycyrrhizin & $0.97 \pm 0.36^{\mathrm{ab}}$ & $0.75 \pm 0.26^{\mathrm{ab}}$ & $3.64 \pm 0.51^{\mathrm{ab}}$ & $421.09 \pm 20.46^{\mathrm{ab}}$ & $56.84 \pm 6.38^{\mathrm{ab}}$ \\
$F$ & 123.370 & 15.760 & 333.820 & 456.390 & 151.880 \\
$P$-value & $<0.001$ & $<0.001$ & $<0.001$ & $<0.001$ & $<0.001$ \\
\hline a $P<0.05$, vs control mice. ${ }^{\mathrm{b}} p<0.05$, vs ARDS mice & & &
\end{tabular}

Table 4: Comparison of expression levels of Nrf2 and its downstream antioxidant enzymes, and AMPK pathwayrelated proteins (mean $\pm \mathrm{SD})$

\begin{tabular}{lccccc}
\hline Group & Nucl-Nrf2 & NQO1 & HO-1 & GCLM & GCLC \\
\hline Control & $0.26 \pm 0.03$ & $0.41 \pm 0.04$ & $0.21 \pm 0.06$ & $0.31 \pm 0.08$ & $0.41 \pm 0.05$ \\
ARDS & $0.58 \pm 0.08^{\mathrm{a}}$ & $0.85 \pm 0.06^{\mathrm{a}}$ & $0.28 \pm 0.08$ & $0.45 \pm 0.09$ & $0.62 \pm 0.06$ \\
Isoglycyrrhizin & $1.16 \pm 0.12^{\mathrm{ab}}$ & $1.06 \pm 0.16^{\mathrm{ab}}$ & $1.02 \pm 0.13^{\mathrm{ab}}$ & $1.25 \pm 0.12^{\mathrm{ab}}$ & $1.02 \pm 0.11^{\mathrm{ab}}$ \\
\hline
\end{tabular}

${ }^{a} P<0.05$, vs control mice; ${ }^{b} p<0.05$, vs ARDS mice 
Table 5: Comparison of NF-kB pathway-related protein levels among the groups (mean \pm SD)

\begin{tabular}{lccc}
\hline Group & p-AMPK/AMPK & p-Akt/Akt & p-GSK3 $\beta / G S K 3 \beta$ \\
\hline Control & $0.35 \pm 0.04$ & $0.3 \pm 0.02$ & $0.21 \pm 0.01$ \\
ARDS & $0.28 \pm 0.04$ & $0.41 \pm 0.03$ & $0.35 \pm 0.02^{\mathrm{a}}$ \\
Isoglycyrrhizin & $0.89 \pm 0.09^{\mathrm{ab}}$ & $1.02 \pm 0.10^{\mathrm{ab}}$ & $0.78 \pm 0.09^{\mathrm{ab}}$ \\
\hline${ }^{\mathrm{a} P}<0.05$, vs control mice; ${ }^{\mathrm{b}} p<0.05$, vs ARDS mice & &
\end{tabular}
Effect of isoglycyrrhizin on NF-KB pathway-
related protein levels

As shown in Figure 4, isoglycyrrhizin significantly downregulated the mRNA and protein expression levels of $p$-IKB and Nucl-p65, but markedly upregulated those of IKBa.

\section{DISCUSSION}

The disease ARDS is a critical medical condition characterized by diffuse pulmonary inflammation, non-cardiogenic pulmonary edema, respiratory failure and other major symptoms. Since symptoms of the disease develop quickly, early diagnosis and treatment are crucial for patients' survival [7].

Isoglycyrrhizin, a flavonoid found in liquorice root, astragalus membranous roots and fructus canthus, possesses anti-inflammatory, antioxidant, cardioprotective, antitumor, antiviral and antibacterial properties [8]. Although isoglycyrrhizin has been reported to be effective against ARDS, the precise molecular mechanism involved remains largely unknown [9]. This research was carried out to elucidate the influence of isoglycyrrhizin on LPS-induced ARDS in mice, and the process involved. Findings from histopathological examination of mice lung tissues suggest that isoglycyrrhizin may effectively ameliorate LPS-induced pathological changes in mice lung tissues, which are consistent with reports from earlier investigations [10].

So far, oxidative stress and inflammatory response are two important mechanisms linked to the pathogenesis of ARDS. Oxidative stress occurs as a result of an imbalance between ROS generation and their neutralization. It causes organ and tissue damage, as well as lipid peroxidation in cell membranes. Inflammatory response refers to the host's response to antigen stimulation or tissue damage [11]. The enzymes INOS and COX-2 mediate inflammation. Lipopolysaccharide (LPS) and a number of cytokines stimulate iNOS expression, thereby promoting the release of pro-inflammatory mediators, and ultimately inflammation.

Cyclooxygenase-2 (COX-2) level is usually low under normal physiological conditions, but increases in response to proinflammatory mediators such as LPS, growth factors, oncogenes and cytokines, as well as mitogenic stimulation. Cyclooxygenase-2 (COX-2) catalyzes the biosynthesis of prostaglandins and enhances vascular permeability, thereby exacerbating ARDS [12]. In this study, the mRNA and protein expression levels of INOS and COX2 were markedly up-regulated in ARDS mice, relative to controls, but they were markedly down-regulated by isoglycyrrhizin. These results indicate that isoglycyrrhizin may alleviate ARDS via inhibition of the inflammatory pathway. It has been reported that long-term stimulation of inflammatory response results in the production of high levels of ROS in pulmonary endothelium, airway epithelium and alveolar cells, thereby causing oxidative stress and severe damage to lung tissue which ultimately aggravates ARDS [13].

Myeloperoxidase (MPO) is a marker of neutrophil accumulation, and its elevation leads to tissue damage. The level of MDA reflects the level of oxidative stress in cells and tissues. Long-term oxidative stress reduces the levels of antioxidants such as SOD and GSH. The findings in the present investigation reveal that treatment of ARDS mice with isoglycyrrhizin markedly reduced the levels of ROS and MDA, as well as activity of MPO in BALF, but it markedly increased the level of GSH, and SOD activity. These results suggest that isoglycyrrhizin could be a potent antioxidant, which is consistent with earlier findings [14].

The Nrf2 pathway, an important antioxidant pathway, is one of the candidate genes for ARDS susceptibility. Changes in Nrf2 level regulate the expressions of antioxidant enzymes such as $\mathrm{HO}$ 1, NQO1, GCLM and GCLC [15]. Phosphorylated AMPK (p-AMPK) is an important upstream regulatory kinase of Nrf2 which promotes Aktmediated phosphorylation of GSK3, and ultimately activates Nrf2. Studies have shown that AMPK pathway is activated by stimuli such as cytokines, growth factors and oxidative stress, and it regulates the transcription of multiple genes such as those involved in inflammation, apoptosis and differentiation [16]. Being a classic inflammatory signaling route, the NF-KB pathway participates in ARDS. Similarly, the activation of NLRP3 is crucial in pathogenesis of ARDS. In 
this study, treatment of ARDS mice with isoglycyrrhizin significantly upregulated the mRNAs and proteins of Nrf2, NQO1, HO-1, GCLM, GCLC, p-GSK3, GSK3, p-AMPK, AMPK, p-Akt, and AKT. These data indicate that the antioxidant and anti-inflammatory effects of isoglycyrrhizin in ARDS mice may be exerted via regulation of AMPK/Nrf2/ARE pathway.

\section{CONCLUSION}

Isoglycyrrhizin protected mice lungs against ARDS via regulation of AMPK/Nrf2/ARE pathway. This finding suggests that this compound may be effective in the treatment of ARDS.

\section{DECLARATIONS}

\section{Conflict of Interest}

No conflict of interest associated with this work.

\section{Contribution of Authors}

We declare that this work was performed by the authors named in this article, and all liabilities pertaining to claims relating to the content of this article will be borne by the authors. Weihua Tan designed the study, supervised the data collection, and analyzed the data. Jian Wang interpreted the data and prepared the manuscript for publication. Zhengliang Peng, Kailiang Huang, Jian Yin, Cheng Feng and Ting You supervised the data collection, analyzed the data, and reviewed the draft of the manuscript.

\section{Open Access}

This is an Open Access article that uses a funding model which does not charge readers or their institutions for access and distributed under the terms of the Creative Commons Attribution License (http://creativecommons.org/licenses/by/ 4.0) and the Budapest Open Access Initiative (http://www.budapestopenaccessinitiative.org/rea d), which permit unrestricted use, distribution, and reproduction in any medium, provided the original work is properly credited.

\section{REFERENCES}

1. Neuschwander $A$, Lemiale $V$, Darmon $M$, Pene $F$, Kouatchet $A$, Perez $P$, Vincent $F$, Mayaux J, Benoit $D$, Bruneel $F$, et al. A Groupe de Recherche en Réanimation Respiratoire en Onco-Hématologie (GRRR-OH) study. Noninvasive ventilation during acute respiratory distress syndrome in patients with cancer:
Trends in use and outcome. J Crit Care 2017; 38: 295299.

2. Fan E, Brodie D, Slutsky AS. Diagnosis and Treatment in Acute Respiratory Distress Syndrome-Reply. JAMA 2018; 320(3): 306.

3. Khorasanchi Z, Shafiee M, Kermanshahi F, Khazaei M, Ryzhikov M, Parizadeh MR, Kermanshahi B, Ferns GA, Avan A, Hassanian SM. Crocus sativus a natural food coloring and flavoring has potent anti-tumor properties. Phytomed 2018; 43: 21-27.

4. Chi JH, Seo GS, Cheon JH, Lee SH. Isoliquiritigenin inhibits TNF- $\alpha$-induced release of high-mobility group box 1 through activation of HDAC in human intestinal epithelial HT-29 cells. Eur J Pharmacol 2017; 796: 101 109.

5. Waziri PM, Abdullah R, Rosli R, Omar AR, Abdul AB, Kassim NK, Malami I, Etti IC, Sani JM, Mohd Lila MA, et al. Clausenidin Induces Caspase 8-Dependent Apoptosis and Suppresses Production of VEGF in Liver Cancer Cells. Asian Pac J Cancer Prev 2018; 19(4): 917-922.

6. World Health Organization. Principles of laboratory animal care. WHO Chron 1985; 39: 51-56.

7. Lucchini A, Bambi S, Mattiussi E, Elli S, Villa L, Bondi $H$, Rona R, Fumagalli R, Foti G. Prone Position in Acute Respiratory Distress Syndrome Patients: A Retrospective Analysis of Complications. Dimens Crit Care Nurs 2020; 39(1): 39-46.

8. Yu H, Zhao Y, Fei JY. Inhibition of SETD7 expression by isoglycyrrhizin can protect myocardial cells from oxidative damage induced by hypoxia/reoxygenation. Tissue Eng Res Chin 2020; 24 (35): 5613-5618.

9. Liu J, Shi XB, Zhang YM. Isoglycyrrhizin can relieve ischemia reperfusion injury in isolated heart of mice. $J$ Yantai Univ 2019; 32(001): 20-24.

10. Ji B, Guo W, Ma H, Xu B, Mu W, Zhang Z, Amat A, Cao $L$. Isoliquiritigenin suppresses $I L-1 \beta$ induced apoptosis and inflammation in chondrocyte-like ATDC5 cells by inhibiting NF-KB and exerts chondroprotective effects on a mouse model of anterior cruciate ligament transection. Int J Mol Med 2017; 40(6): 1709-1718.

11. Adamiak M, Abdelbaset-Ismail A, Moore JB 4th, Zhao J, Abdel-Latif A, Wysoczynski M, Ratajczak MZ. Inducible Nitric Oxide Synthase (iNOS) Is a Novel Negative Regulator of Hematopoietic Stem/Progenitor Cell Trafficking. Stem Cell Rev Rep 2017; 13(1): 92-103.

12. Al-Harbi NO, Nadeem A, Ansari MA, Al-Harbi MM, Alotaibi MR, AlSaad AM, Ahmad SF. Psoriasis-like inflammation leads to renal dysfunction via upregulation of NADPH oxidases and inducible nitric oxide synthase. Int Immunopharmacol 2017; 46: 1-8.

13. Li HL, Sun BZ, Ma FC. Expression of COX-2, iNOS, p53 and Ki-67 in gastric mucosa-associated lymphoid tissue lymphoma. World J Gastroenterol 2004; 10(13): 18621866.

14. Jiang W, Geng H, Lv X, Ma J, Liu F, Lin P, Yan C. Idebenone Protects against Atherosclerosis in Apolipoprotein E-Deficient Mice Via Activation of the

Trop J Pharm Res, October 2021; 20(10): 2075 
SIRT3-SOD2-mtROS Pathway. Cardiovasc Drugs Ther 2020. doi: 10.1007/s10557-020-07018-5. Epub ahead of print.

15. Lv H, Liu Q, Wen Z, Feng H, Deng X, Ci X. Xanthohumol ameliorates lipopolysaccharide (LPS)-induced acute lung injury via induction of AMPK/GSK3 $\beta-N r f 2$ signal axis. Redox Biol 2017; 12: 311-324.
16. Liu L, Wu W, Li J, Jiao WH, Liu LY, Tang J, Liu L, Sun F, et al. Two sesquiterpene aminoquinones protect against oxidative injury in $\mathrm{HaCaT}$ keratinocytes via activation of AMPKa/ERK-Nrf2/ARE/HO-1 signaling. Biomed Pharmacother 2018; 100: 417-425. 